${ }^{1}$ Doutora em Direito do Trabalho e Sindical pela Universidade Degli Studi di Roma - LA SAPIENZA - com revalidação sucessiva pela Universidade de São Paulo - USP. Pós-doutora em Direito junto à Pontifícia Universidade Católica PUCSP. Pós-Graduada em Economia do Trabalho (Curso de Especialização) pela UNICAMP. Juíza do Trabalho aposentada (TRT. $9^{a}$ Região-Paraná). Autora de livro e de inúmeros artigos publicados em obras coletivas e revistas jurídicas. Professora Universitária em Curso de Mestrado Profissional das Faculdades Londrina e em Cursos de Especialização em Direito do Trabalho.

E-mail: dinauragomes@sercomtel.com.br Orcid:

https://orcid.org/0000-0002-7274-9251

\section{TRABALHO DECENTE DIANTE DE INCERTEZAS ADVINDAS DAS INOVAÇÕES TECNOLÓGICAS DA ERA DIGITAL}

\author{
DECENT WORK IN THE FACE OF UNCERTAINTIES ARISING FROM THE \\ TECHNOLOGICAL INNOVATIONS OF THE DIGITAL AGE
}

\section{Dinaura Godinho Pimentel Gomes ${ }^{1}$}

Como citar: GOMES, Dinaura Godinho Pimentel. Trabalho decente diante de incertezas advindas das inovações tecnológicas da era digital. Revista do Instituto de Direito Constitucional e Cidadania - IDCC, Londrina, v. 6, n. 1, e021, jan/jun, 2021. ISSN: 2596-0075. DOI: 10.48159/revistadoidcc.v6n1.e021

Resumo: O avanço da tecnologia de plataformas tem propiciado a precarização do trabalho. $\mathrm{O}$ acesso ao trabalho decente e a manutenção do emprego passaram a depender inexoravelmente da educação e do contínuo desenvolvimento das capacidades e potencialidades humanas, para adequação às atuais exigências do mercado econômico globalizado. $\mathrm{O}$ direito à educação de qualidade e o direito ao trabalho para todos são os meios indispensáveis para o exercício da cidadania em prol do desenvolvimento e da sustentabilidade econômica do País. Nesse contexto de modernidade tecnológica, a Justiça do Trabalho, com sua competência ampliada em face da Emenda Constitucional n. 45/2004, tem plenas condições de adaptar e aplicar a legislação do trabalho, à luz da Constituição Federal, no julgamento de conflitos que envolvem novas relações de trabalho. Assim, tem como impedir que muitos trabalhadores sob demanda via aplicativos continuem sendo injustamente descartados da proteção jurídica e transferidos para a informalidade.

Palavras-chave: educação de qualidade; trabalho decente; justiça do trabalho.

\begin{abstract}
The advancement of platform technology has led to job instability. Access to decent work and the maintenance of employment have become inexorably dependent on education and the continuous development of human capacities and potentialities to adapt to the current demands of the globalized economic market. The right to quality education and the right to work for all are the indispensable means to practice citizenship in favor of the development and economic sustainability of the country. In this context of technological modernity, Labor Justice, with its competence broadened in the face of the Constitutional Amendment n. 45/2004, is fully capable of adapting and applying the labor legislation, in light of the Federal Constitution, in the judgment of conflicts that involve new labor relations. Thus, it can prevent many on-demand workers via applications from being unfairly excluded from legal protection and transferred to informality.
\end{abstract}

Keywords: quality education; decent work; labor justice. 


\section{INTRODUÇÃO}

É através do trabalho que a maioria da população econômica ativa encontra meios viáveis para o alcance de uma vida digna. E é o acesso ao trabalho decente que possibilita a cada pessoa seu desenvolvimento como Ser Social, a expansão do sentimento de pertença a induzir o livre exercício da cidadania, como sujeito de direitos e deveres, no âmbito do Estado Democrático de Direito.

No entanto, com a expansão da quarta revolução industrial, a partir do final do século $\mathrm{XX}$, o acesso aos novos postos de trabalho passou a depender de notável conhecimento e qualificação profissional dos trabalhadores, provenientes de formação educacional de qualidade. A realidade aponta que a situação deficitária da educação constatada no Brasil, além de não proporcionar eficaz aprendizagem no ensino fundamental e médio, obsta a busca do conhecimento e a consequente formação técnica, profissional e universitária de pessoas para o ingresso e permanência no mercado de trabalho da atualidade. Ademais, as inovações tecnológicas dão ensejo à feição virtual do poder empregatício, à excessiva flexibilização e à precarização das relações de trabalho.

Nesse contexto, ainda falta aos órgãos do Poder Executivo, a quem se atribui a responsabilidade pelos atos de governo e administração do Estado, desenvolver sérias estratégias e políticas públicas concernentes à elevação do nível da educação e o acesso a todos sem qualquer discriminação, para preservar o SER HUMANO, centro de imputação jurídica. A partir daí, em vista do progresso social, devem estimular a busca por mais solidariedade dos agentes econômicos, para o fortalecimento de uma sociedade em rede, a induzir o aumento da produtividade e a melhoria da competitividade, no âmbito de uma economia digital globalizada, porém mediante contínuo aperfeiçoamento do capital humano para o enfrentamento de inafastáveis reformas estruturantes.

Em vista das extraordinárias mudanças de traço hiper-tecnológico, o Direito do Trabalho, por meio de seus princípios e regras, tem como regular os reflexos decorrentes nas relações de trabalho, a viabilizar o convívio harmônico das partes voltado ao respeito dos princípios da dignidade humana e do valor social do trabalho, principalmente diante da utilização das plataformas de relacionamento digital.

Nessa mesma direção, compete ao Judiciário Trabalhista fazer valer a Constituição Federal, repudiando de forma enérgica a mera prevalência de interesses econômicos voltada exclusivamente à acumulação da renda e ao aumento desmesurado das margens de lucro, 
todavia, em prejuízo da efetivação de direitos trabalhistas. Tais condutas ilícitas patronais, que extrapolam o exercício do poder diretivo, refletem a negação dos valores, princípios e regras constitucionais, bem como das normas internacionais de proteção dos direitos humanos, aliadas à legislação ordinária. Emerge daí a importância da prestação jurisdicional trabalhista voltada à realização da justiça, resgatando o respeito e proteção da dignidade humana. Portanto, a atuação do Poder Judiciário trabalhista, com racionalidade e sensibilidade, tem como adequar o Direito do Trabalho à realidade do desenvolvimento tecnológico da era digital, para afastar a precariedade e a informalidade, espelhada na criação de diferentes tipos de contratos de trabalho, principalmente daqueles que envolvem a prestação de serviços dirigida por plataformas. É o que se pretende tratar neste ensaio.

\section{Trabalho DIGNO DEPENDENTE DA EDUCAÇÃO DE QUALIDADE}

Desde as últimas décadas do século XX, o conhecimento tem sido cada vez mais a base da economia a gerir os mercados que dominam as nações, mediante a célere e continuada expansão das inovações tecnológicas a envolver o capital, novos talentos, grandes empresas e a explosão dos sistemas de telecomunicações. Assim, emergem as fortes tendências de intensificação da concorrência baseadas não apenas na quantidade mas na qualidade de produção embasada principalmente no processamento de informações. Nesse contexto, a globalização das atividades econômicas apresenta-se revigorada sob outras formas organizacionais que passam a fazer parte das políticas das nações. Por decorrência, provoca a redução da autonomia dos Estados no controle da geração de suas riquezas em seus próprios territórios, o que afeta a justa distribuição de benefícios sociais.

Convém destacar a adoção de diferentes estratégias coordenadas em busca do aumento da competitividade a impor o crescimento econômico decorrente da elevação da produtividade baseada na formação de capital humano, o que, por primeiro, depende de incentivos à educação de qualidade para a criação de novas formas de emprego. É o que preleciona Jean Tirole:

\footnotetext{
Para criar empregos, precisamos de uma cultura e um ambiente empresarial. Também precisaremos de universidades de nível mundial para não perdermos esse momento decisivo da história econômica em que conhecimento, análise de dados e criatividade estarão no centro da cadeia de valor. Com efeito, o campus universitário é de certa forma um condensado de todas essas transformações da empresa: cooperações mais horizontais, valorização da criatividade, multiatividade, necessidade de exprimir-se em seu trabalho. ${ }^{1}$
}

1 TIROLE, Jean. Economia do bem comum. Trad. André Telles. Rio de Janeiro: Zaar, 2020, p. 434. 
A educação de qualidade, por conseguinte, fortalece o vínculo social do indivíduo com a sociedade, o que facilita o relacionamento entre o Estado e as instituições econômicas e financeiras em vista do alcance do bem comum. Pode enaltecer a solidariedade e o compromisso com a ética. A participação social, exigida no seio de uma sociedade democrática, depende, pois, dessa melhoria da educação através de políticas públicas coordenadas e revigorantes, de modo a propiciar a formação moral e holística de toda pessoa, justamente por se tratar de um direito fundamental.

No âmbito do patamar civilizatório estabelecido pelas normas dos Tratados Internacionais dos Direitos Humanos, insere-se o direito fundamental à educação como um desses direitos, conforme vem proclamado pela Declaração Universal dos Direitos Humanos (adotada pela Resolução n.217 A (III) da Assembleia Geral das Nações Unidas, em 10 de dezembro de 1948) e pelo Pacto Internacional dos Direitos Econômicos Sociais e Culturais, resultante da juridicização da citada Declaração (adotado pela XXI Sessão da Assembleia Geral das Nações Unidas, em 19 de dezembro de 1966 e ratificado pelo Brasil em 6 de julho de 1992), que assim preceitua em seu

\begin{abstract}
Artigo 13-1. Os Estados Partes do presente Pacto reconhecem o direito de toda pessoa à educação. Concordam em que a educação deverá visar ao pleno desenvolvimento da personalidade humana e do sentido de sua dignidade e fortalecer o respeito pelos direitos humanos e liberdades fundamentais. Concordam ainda em que a educação deverá capacitar todas as pessoas a participar efetivamente de uma sociedade livre, favorecer a compreensão, a tolerância e a amizade entre todas as nações e entre todos os grupos raciais, étnicos ou religiosos e promover as atividades das Nações Unidas em prol da manutenção da paz. ${ }^{2}$.
\end{abstract}

Emerge do teor desta norma que a educação é a base necessária para se efetivar outros direitos humanos, dos quais ora se destaca o direito ao trabalho, sendo assim essencial para a realização de toda pessoa em suas diversas dimensões, além de garantir a paz, a tolerância de um modo geral e a solidariedade. Assim, é através da realização do direito à educação que se pode alcançar um desenvolvimento integral da pessoa humana. Nessa senda, verificam-se importantes propósitos de manutenção e expansão contínua de esforços por parte de instituições internacionais, a congregar várias nações em prol da educação de qualidade para todos.

Inquestionavelmente, o poder transformador da educação é considerado como a maior ferramenta para se atingir o pleno emprego e a erradicação da pobreza, ao fomentar o desenvolvimento de habilidades relevantes direcionadas ao desempenho de pontuais

2 Pacto Internacional de Direitos Econômicos Sociais e Culturais in: PIOVESAN, Flávia. Direitos Humanos e o Direito Constitucional Internacional. $18^{\mathrm{a}}$ edição. São Paulo: Saraiva, 2018, p. 559. 
competências técnicas e profissionais. Além disso, a educação tem sido invocada como meio de inclusão social a favorecer a promoção da democracia e dos direitos humanos, da cidadania global e do engajamento civil, bem como do desenvolvimento sustentável.

No Brasil, a educação se apresenta inserida no rol dos direitos fundamentais sociais, conforme está previsto no art. $6^{\circ}$, da Constituição da República Federativa do Brasil. Está configurada, portanto, como uma das devidas prestações positivas por parte do Estado, em favor do pleno desenvolvimento de toda e qualquer pessoa. A especificação mais detalhada do direito à educação consta dos arts. 205 a 214, da mesma CRFB, sendo certo que o artigo 205 assim dispõe: “A educação, direito de todos e dever do Estado e da família, será promovida e incentivada com a colaboração da sociedade, visando ao pleno desenvolvimento da pessoa, seu preparo para o exercício da cidadania e sua qualificação para o trabalho".

Desse modo, impõe-se reforçar a responsabilidade constitucional do Estado no tocante à implementação do direito à educação para todos, em níveis bem mais eficientes e satisfatórios. É a base necessária para se obter formação, cultura e desenvolvimento, principalmente o indispensável preparo e qualificação para o acesso ao trabalho digno e, por decorrência, o pleno exercício da cidadania tal como proclama a Lei Maior. Nesse sentido, eis a aferição de Richard Pae Kim:

\begin{abstract}
O texto do art. 205 da Constituição Federal, portanto, vincula a educação à formação da cidadania. A educação que não prepara o indivíduo para ser titular da cidadania e poder efetivamente exercê-la o marginaliza, o exclui do contexto de uma sociedade justa e igualitária e refrata o sistema da vida do indivíduo, seja não só pela omissão na prestação do serviço educacional (privado ou público), mas também quando a educação não se volta para a formação desta cidadania, quando ela é prestada de forma ineficiente e incompleta. ${ }^{3}$
\end{abstract}

Cumpre acrescentar o disposto no art. 26, da Lei 12.965, de 24 de abril de 2014, considerada como Marco Civil da Internet, que salienta a promoção do exercício do direito à educação como dever constitucional do Estado:

Art. 26. O cumprimento do dever constitucional do Estado na prestação da educação, em todos os níveis de ensino, inclui a capacitação, integrada a outras práticas educacionais, para o uso seguro, consciente e responsável da internet como ferramenta para o exercício da cidadania, a promoção da cultura e o desenvolvimento tecnológico. ${ }^{4}$

3 KIM, Richard Pae. O Conteúdo Jurídico da Cidadania na Constituição Federal do Brasil. In: MORAES, Alexandre; KIM, Richard Pae (Coords.). Cidadania. O novo conceito jurídico e a sua relação com os direitos fundamentais individuais e coletivos. São Paulo: Editora Atlas S/A, 2013, p. 31.

4 BRASIL, Lei 12.965, de 24 de abril de 2014. Disponível em < http://www.planalto.gov.br/ccivil_03/ato20112014/2014/lei/112965.htm>. Acesso em: 27fev. 2021. 
Apesar dos princípios e regras constitucionais, que dão prevalência às normas dos Tratados Internacionais dos Direitos Humanos devidamente ratificados, constata-se que, no País, conforme já destacado, ainda faltam estímulos, investimentos e eficiente ação pública voltados à melhoria de uma educação básica, seguida de um encaminhamento eficaz ao ensino médio e superior. Com isso, emergem sérias dificuldades para a formação de trabalhadores condizente com os requisitos necessários à assunção de novas condições de trabalho num mundo de negócios movido pela necessidade de operar com mais velocidade, criatividade e eficiência sem precedentes nesta era do conhecimento, a fortalecer o desenvolvimento da inteligência artificial, dentre outras transformações importantes.

Assim, mudanças estruturais imediatas são essenciais, no campo da educação, para o enfrentamento de grandes desafios advindos da integração dos mundos físico e digital, que alteram substancialmente o modo e o conteúdo das prestações laborais, cada vez mais dependentes do alto nível de capacitação e gestão, para o acesso a postos de trabalho.

Eis as pertinentes perspectivas lançadas por Hubert Alquéres:

A OCDE é um fórum multinacional. Entre suas ações voltadas para a educação está o Pisa, respeitado sistema internacional da avaliação do ensino, cujos resultados servem de parâmetro para países identificarem a qualidade de sua educação e, a partir daí, traçar políticas públicas para a sua melhoria.

A inquietude tem razão de ser quando se leva em consideração dados do Fórum Econômico Mundial, segundo os quais $65 \%$ dos trabalhos que os jovens, que hoje estão na educação básica, realizarão ao final de seu percurso escolar, ainda nem foram inventados. Estima-se que, em um período de dez a quinze anos, $47 \%$ dos atuais postos de trabalho desaparecerão, com a robótica e a inteligência artificial, substituindo o homem em atividades rotineiras; manuais ou intelectuais.

Nesse quadro, o desafio da educação é formar jovens para empregos que ainda não foram criados, para tecnologias ainda não inventadas, para solucionar problemas que não foram previstos ainda, mas que serão uma realidade quando concluírem seu ciclo escolar e estiverem aptos a ingressar no novo mercado de trabalho. ${ }^{5}$

Diante de tais probabilidades, não se pode mais tolerar esse real e dominante descaso do Poder Público com a educação no País, que se manifesta pela escassez de investimentos de toda ordem, com mais ênfase daqueles voltados à condizente formação de professores, sua valorização e seu reconhecimento, inclusive mediante o pagamento de uma justa e compatível remuneração. Como contraponto, e a título de exemplo, impõe-se destacar a educação pública de qualidade em Singapura, dentre outros países que têm sido considerados excelência na

ALQUÉRES, Hubert. O Novo Conhecimento. O desafio da educação é formar jovens para empregos que ainda não foram criados. In: Revista Cult, no 246. São Paulo: Editora Bregantini, junho de 2019, p.39. 
educação, tais como, Finlândia, Alemanha, Coréia do Sul, Japão, Canadá e Estados Unidos, entre outros, com bem realça Carolina Alves de Souza Lima:

\begin{abstract}
Singapura é hoje uma democracia parlamentar e tem o maior índice de desenvolvimento humano entre os países asiáticos, sendo o sexto colocado no ranking mundial. É um país com altíssima qualidade de vida, o que reflete na qualidade do seu sistema educacional. $O$ país foi o mais bem classificado entre os países avaliados pelo Pisa em 2015 [...].

Verifica-se, claramente, por meio das informações fornecidas pelo Ministério da Educação de Singapura, que o objetivo maior é formar cidadãos para os desafios do século 21 . Visa à educação holística, na qual a escola trabalha a autoconfiança dos alunos e o desejo de aprender. Segundo o Ministério da Educação, para que os alunos estejam preparados para prosperar no século 21 , diante da globalização e dos avanços tecnológicos, a escola primária visa a proporcionar o desenvolvimento de várias dimensões da pessoa humana [..].

As autoridades públicas na área da educação escolar têm defendido uma visão mais ampla de sucesso, muito além das notas acadêmicas, porquanto focada no desenvolvimento integral do ser humano e na sua forma de se relacionar com a vida, o trabalho e a sociedade. O país continua ativamente comprometido em permanecer como um dos melhores sistemas de educação do mundo. ${ }^{6}$
\end{abstract}

Lamentavelmente e com certas exceções, no Brasil, os Poderes Públicos não buscam a melhoria da situação deficitária da educação, deixando de proporcionar uma eficiente aprendizagem. Assim, essas sérias omissões enfraquecem e minimizam a busca contínua do conhecimento, para a inserção e permanência no mercado de trabalho cada vez mais flutuante, além de afrontar a prevalência dos direitos humanos (CRFB, art. $4^{\circ}$, II).

A realidade atual ainda aponta a frágil busca por permanentes parcerias entre organizações público-privadas e instituições estatais competentes, para ampliar o volume de investimentos sociais nessa área. Ao contrário, simplesmente são lançadas duras medidas de contingenciamento de recursos financeiros na educação, ao invés de se dar à mesma a necessária prioridade de garantia e realização. Ora, é a partir de uma educação de qualidade que se pode concretizar um projeto de desenvolvimento sustentável capaz de possibilitar a inclusão social da população econômica ativa, em sintonia com os fins da verdadeira justiça social, erradicando a pobreza e reduzindo as desigualdades sociais (CRFB, art. $3^{\circ}$, inciso III). No entanto, convém lembrar que o nível de desigualdade no Brasil é um dos mais elevados do mundo, porquanto milhares de pessoas não têm acesso à educação, sendo muitas analfabetas (IBGE, 2019). ${ }^{7}$

6 LIMA, Carolina Alves de Souza. Cidadania, Direitos Humanos e Educação: avanços, retrocessos e perspectivas para o século 21. São Paulo: Almedina, 2019, p.105/107.

7 IBGE. "Pesquisa Nacional por Amostra de Domicílio (PNAD). Ministério da Educação. No Brasil, o analfabetismo alcança 10,3\% dos idosos brancos e 27,5\% dos pretos ou pardos. Em 2018, havia 11,3 milhões de pessoas com 15 anos ou mais de idade analfabetas, o equivalente a uma taxa de analfabetismo de 6,8\%. Em relação 
Por isso, impõe-se dar relevante prioridade aos investimentos públicos em educação tendentes ao alcance de uma ordem futura lastreada no conhecimento, na atualização da cultura e na formação da personalidade humana. Somente assim haverá mais condições de se expandir conhecimentos, principalmente quando envolvem tecnologia e inovação compatíveis com as exigências advindas da quarta revolução industrial, facilitando o indispensável acesso ao trabalho digno.

\section{DIREITO AO TRABALHO DECENTE NO ÂMBITO DA SOCIEDADE DIGITALIZADA E A RELEVÂNCIA DA ATUAÇÃO DA JUSTIÇA DO TRABALHO}

O crescimento econômico, na atualidade, passou a depender da expansão da tecnologia inovadora avançada - e cada vez mais sofisticada - para abertura de novos mercados. Com isso, o acesso aos novos postos de trabalho ficou bem restrito, dependendo, não raro, da consentânea capacitação de trabalhadores.

Como se sabe, a inicial difusão do termo Quarta Revolução Industrial ocorreu em 2012, em Hannover, Alemanha, sendo certo também que, em janeiro de 2017, no Fórum Econômico de Davos, foram apresentados alguns dos elementos marcantes dessa Revolução 4.0, concentrada para o uso das nanotecnologias, neurotecnologias, biotecnologias, robôs, inteligência artificial, drones, sistemas de armazenamento de energia e impressora 3D.

Klaus Schwab, fundador e presidente executivo do Fórum Econômico Mundial, ressalta as contemporâneas mudanças ocorrentes no mundo do trabalho, diante da introdução das inovações tecnólogicas dessa quarta revolução industrial, voltadas a elevar a competitividade num contexto global. São relevantes as transformações que atingem primordialmente as relações de trabalho, ensejando a criação de novos tipos de empregos e o aniquilamento de muitos outros, hoje existentes. Assim, salienta que "o talento, mais que o capital, representará o fator crucial da produção. Por essa razão, a escassez de uma força de trabalho capaz, mais que a disponibilidade de capital, terá mais probabilidade de constituir o limite incapacitante da inovação". Para ele, "a quarta revolução industrial exigirá e enfatizará a capacidade dos

a 2017, houve uma queda de 0.1 p.p., o que corresponde a uma redução de 121 mil analfabetos entre os dois anos. Quanto mais velho o grupo populacional, maior a proporção de analfabetos. Em 2018, eram quase 6 milhões de analfabetos com 60 anos ou mais, o que equivale a uma taxa de analfabetismo de 18,6\% para esse grupo etário. Em 2018, no Brasil, 47,4\% das pessoas de 25 anos ou mais haviam completado, pelo menos, a educação básica obrigatória. Ou seja, 52,6\% não chegaram a concluir o ensino médio, o equivalente a 70,3 milhões de pessoas". (IBGE,

Disponível: $<$ https://agenciadenoticias.ibge.gov.br/media/com_mediaibge/arquivos/00e02a8bb67cdedc4fb22601e d264c00.pdf $>$ acesso em: 27abr.2021. 
trabalhadores em se adaptar continuamente e aprender novas habilidades e abordagem dentro de uma variedade de contextos". 8

A notória expansão da economia direcionada por inovações permanentes, através da tecnologia, informação e comunicação, passa a exigir uma força de trabalho altamente capacitada, em pleno uso de suas potencialidades decorrentes de elevado conhecimento técnico, profissional e acadêmico, para gerar negócios e aumento das possibilidades de crescimento. Direciona-se à flexibilização na gestão do trabalho, ao aumento da automação no desenvolvimento das atividades repetitivas e, por isso, à busca por trabalhadores bem mais preparados no uso de ferramentas tecnológicas, com criatividade e mais autonomia, para ampliar as perspectivas industriais.

Em outros termos, a introdução da inteligência artificial vai muito além do uso da robótica, eis que provoca também a brutal transformação da organização do trabalho. Dá ensejo à considerável exclusão de trabalhadores e a contratação de outros para o desempenho de funções fora do modelo tradicional de contrato individual de trabalho protegido por lei, para empresas como UBER, IFOOD, e UBER EATS, em afronta às normas constitucionais e da Consolidação das Leis do Trabalho, recentemente atualizada pela Reforma Trabalhista (Lei 13.467/2017 e Lei 13.840/2019).

Todas as incertezas advindas da expansão e dos impactos da Inteligência Artificial devem ser bem sopesadas pelos governos democráticos, a fim de bem administrar seus efeitos, de modo a propiciar efetivamente o progresso social de forma mais inclusiva, à luz dos direitos humanos fundamentais. A eventual omissão certamente poderá induzir a evolução do caráter disruptivo das inovações daí advindas, de modo a favorecer a lógica destrutiva do capital em prejuízo das aspirações democráticas e, mais precisamente, da evolução da classe de trabalhadores.

A propósito, Kai-Fu Lee chama a atenção para o devido controle em relação a essa tecnologia, salientando o seguinte:

Com a enxurrada diária de manchetes sobre IA, é fácil sentir como se os seres humanos estivessem perdendo o controle sobre o próprio destino. Profecias tanto de senhores-robôs quanto de uma "classe inútil" de trabalhadores desempregados tendem a se misturar em nossas mentes, evocando uma sensação avassaladora de desamparo humano diante de todas essas tecnologias poderosas. Esses cenários apocalípticos contêm um núcleo de verdade sobre o potencial da IA, mas os sentimentos de desamparo que eles geram obscurecem um ponto-chave: quando se trata de moldar o

8 SCHWAB, Klaus. A Quarta Revolução Industrial. Trad. Daniel Moreira Miranda. São Paulo: Edipro, 2016, p. 15,16 e 51 . 
futuro da inteligência artificial, o fator mais importante será como agirão os seres humanos. ${ }^{9}$

Nessa senda, o autor realça a capacidade do ser humano de traçar seus próprios objetivos, o que motiva sua capacidade de evoluir cada vez mais com o avanço das novas tecnologias como a inteligência artificial:

\begin{abstract}
Não fomos colocados na Terra somente para trabalhar em tarefas repetitivas. Não precisamos passar nossa vida acumulando riqueza apenas para morrermos e passá-las para nossos filhos - a última "iteração do algoritmo humano -, que irão refinar e repetir esse processo.

Se acreditarmos que a vida tem um significado além dessa corrida desenfreada material, então a IA pode vir a ser a ferramenta que nos ajudará a descobrir o significado mais profundo. ${ }^{10}$
\end{abstract}

No entanto, a formação das relações de trabalho através das plataformas digitais, que tem sido defendida por empresas que integram a chamada Gig Economy - considerado como um sistema colaborativo formado por "empreendedores de si mesmo" -, ao invés de conduzir o desenvolvimento tecnológico em prol da melhoria do status dos trabalhadores condizente com seus direitos fundamentais, em verdade, provocam um retrocesso social e precarização das relações de trabalho.

Mesmo assim, uma multidão de trabalhadores busca a utilização do aplicativo Uber, na condição de motorista conectado com o GPS, para preencher os requisitos estabelecidos pela empresa e obter a devida permissão. Fazendo a devida opção, dentre várias alternativas, eles obtêm a estimativa de preço a ser cobrado de clientes, consumidores, porém sem qualquer direito e amparo das leis trabalhistas, por parte da aludida empresa.

Ora, esses trabalhadores, embora sob a roupagem de trabalhadores independentes, considerados sem vínculo empregatício, permanecem de fato sob a constante dependência dessa empresa, sujeitando-se às regras preestabelecidas no decorrer de longas jornadas, para garantir um mínimo de remuneração. Bem ao contrário das alegações justificadoras de sua autonomia, seu trabalho é controlado por plataforma, podendo até ser desligado abruptamente. Além disso, a empresa Uber fixa o percentual dos valores cobrados dos consumidores, por meio dos motoristas. Ademais, esses trabalhadores, juntamente com aqueles entregadores de plataformas digitais, são excluídos da proteção dos direitos trabalhistas, em que pese a real subordinação

\footnotetext{
9 LEE-KAI FU. Inteligência artificial: como os robôs estão mudando o mundo, a forma como amamos, nos comunicamos e vivemos. Trad. Marcelo Barbão. Rio de Janeiro: Globo Livros, 2019, p. 271-272.

10 Idem.
} 
jurídica, levando-se em conta ainda o disposto no parágrafo único do art. $6^{\circ}$ da Consolidação das Leis do Trabalho. Em vista de tal situação, não se pode negar que tal empresa depende desses trabalhadores, pois, sequer existiria sem eles para o desenvolvimento de sua atividadefim (transporte de pessoas e de entrega de alimentação), fazendo uso de suas plataformas digitais de trabalho.

A propósito, urge ressaltar que o requisito legal da subordinação jurídica não perdeu sua essencialidade tradicional para a caracterização da relação de emprego clássica. Tratando-se de serviços prestados à empresa Uber, por exemplo, a subordinação deve ser reavaliada juntamente com os elementos previstos nos artigos $2^{\circ}$ e $3^{\circ}$ da CLT, por força das diferentes modalidades de prestação de serviços em favor de estruturas organizacionais, notadamente aquelas jungidas ao corporativismo de plataforma.

\begin{abstract}
Os predicamentos da subordinação, presentes na relação de emprego tradicional (tais como o poder de modulação, o poder de fiscalização e o poder punitivo), são, em parte, coletivizados para a multidão de consumidores, que avalia a qualidade do serviço; e, noutra parte, permanecem nas mãos da Uber, já que é ela quem traça as diretrizes (contratuais, inclusive) de quantas corridas é possível o motorista não aceitar ou qual a nota mínima (dadas pelos consumidores, é verdade) que ele deve ter para continuar cadastrado no aplicativo.
\end{abstract}

Assim, a subordinação clássica (subjetiva), tal como construída a partir do art. $3^{\circ}$ da CLT, parece não mais se evidenciar com tanta clareza, deixando espaço para discussões acerca da subordinação objetiva (em face da realização, pelo trabalhador, dos objetivos sociais da empresa) ou estrutural (harmonizando-se o trabalhador à organização, dinâmica e cultura do empreendimento que lhe capta os serviços), as quais poderiam sufragar, em leituras alternativas, a configuração do vínculo empregatício. ${ }^{11}$

Com efeito, o capitalismo, por si mesmo, não promove o desenvolvimento social, como é notório. Por isso, a resolução das sérias dificuldades de cunho humano, ocorrentes no mundo do trabalho, não pode ser entregue ao livre jogo das forças de mercado. Inexoravelmente, os ideólogos neoliberais são voltados à priorização da economia do mercado livre, de modo a diminuir a atuação do Estado, inclusive no campo social, em vista da preservação de estruturas capitalistas descompromissadas com os valores democráticos. Sustentam o desempenho da livre iniciativa de modo absoluto, afastando as empresas de sua função social, principalmente diante da atual revolução globalizada da tecnologia e informação.

11 FELICIANO, Guilherme Guimarães; PASQUALETO, Olívia de Quintana Figueiredo. (Re)descobrindo o Direito do Trabalho: Gig Economy, Uberização do trabalho e outras reflexões. In: Guilherme Guimarães Feliciano, Ana Paula Silva Campos Miskulin (Coords.). Infoproletários e a Uberização do Trabalho: direito e justiça em um novo horizonte de possibilidades. São Paulo: LTr, 2019, p. 16. 
Em vista disso, cumpre destacar a Lei 13.874, de 20 de setembro de 2019, que, ao instituir a Declaração de Direitos de Liberdade Econômica, realça expressamente a atuação do Estado na condição de agente normativo e regulador da Ordem Econômica, em total sintonia com o disposto nos termos dos artigos 170, IV, e 174 da Constituição da República Federativa do Brasil. Apesar dessa necessária ação fiscalizadora do Estado, assim prevista, empresas multinacionais e transnacionais, em regra, procuram agir sem a observância de quaisquer limites, fragilizando os controles e as intervenções públicas dos Estados-nação de um modo geral, bem como a livre concorrência. A respeito, eis o que Paul Collier preleciona:

\begin{abstract}
O surgimento da economia digital criou nossas indústrias em rede que podem se ampliar e ter um monopólio global. Essas empresas precisam de pouquíssimo capital em sua definição convencional - os ativos tangíveis de instalações e equipamentos. O valor delas é um ativo intangível: são suas redes. Ao contrário dos ativos tangíveis, é muito difícil serem reproduzidas pelos concorrentes; são imateriais, e por isso não têm uma localização fixa sujeita a políticas públicas. O Facebook, o Google, o Amazon, o eBay e a Uber são, todos eles, exemplos de redes que tendem para o monopólio global natural em seus nichos específicos. Como monopólios naturais de propriedade privada, não sujeitos a regulações, podem representar enormes perigos. ${ }^{12}$
\end{abstract}

Não se pode ignorar, por conseguinte, que as alterações introduzidas pela sociedade em rede estão em consonância com a internacionalização da produção sem fronteiras, a exigir, por meios tecnológicos, a prestação de serviços no universo de um mercado empresarial cada vez mais flexível, sem a fixação de um lugar específico e predeterminado. Mesmo assim, sob a proteção do Estado Democrático de Direito, merecem ter prioridades os investimentos na melhoria do capital humano que congreguem conhecimentos voltados à prática de habilidades diversificadas. Desse modo, haverá mais condições de propiciar, no País, a formação de trabalhadores devidamente capacitados e bem mais criativos para adequação a essas constantes mudanças no âmbito empresarial

Por tudo isso, no contexto da contínua evolução das inovações tecnológicas, grande parte das empresas assume um novo perfil organizacional voltado à eliminação ou redução de uma estrutura hierarquizada em prol da formação de solidárias equipes de trabalho, compostas por empregados eficientes e qualificados. Além da colaboração interna, cada empresa passa a depender de alianças com outras empresas, entidades universitárias e, até mesmo, de estratégias do próprio governo local, para salvaguardar sua sobrevivência, como bem destaca Ladislau Dowbor:

12 COLLIER, PAUL. O Futuro do Capitalismo: enfrentando as novas inquietações. Trad. Denise Bottmann. Porto Alegre: L\&PM, 2019, p. 102. 
Ao tornar-se o conhecimento crescentemente o principal fator de produtividade, e já que o conhecimento compartilhado não tira conhecimento de ninguém, ao contrário, tende a multiplicar-se, a evolução natural não é a de nos trancarmos numa floresta de patentes e proibições, mas sim de criar ambientes colaborativos abertos [...]. As redes interuniversitárias de colaboração nesse sentido estão demonstrando caminhos mais inteligentes e modernos ainda que o grosso do mundo universitário tenda também a se proteger nas suas torres [...].

Ou seja, a construção de processos colaborativos necessários a uma economia moderna passa por romper os diversos tipos de fortificações que constituem os cartéis, trustes e outros clubes de ricos que desequilibram o desenvolvimento. Não há como escapar à busca ativa de processos econômicos mais democráticos, descentralizados e participativos.

A democracia econômica constitui um complemento necessário que pode racionalizar tanto a política como a economia. ${ }^{13}$

A junção de fatores favoráveis ao bem-estar de todos deve ser a meta da Administração Pública, sob pena de a grande maioria da população perecer por força da exclusão social cada vez mais agravada. Portanto, imperioso se torna fazer valer a Constituição Federal, principalmente em face do que dispõe o art. $3^{\circ}$ da CRFB, ao traçar os seguintes objetivos fundamentais da República Federativa: “I - construir uma sociedade livre, justa e solidária; II - garantir o desenvolvimento nacional; III - erradicar a pobreza e a marginalização e reduzir as desigualdades sociais e regionais; IV - promover o bem de todos, sem preconceitos de origem, raça, sexo, cor, idade e quaisquer outras formas de discriminação".

Deriva dessa norma constitucional a fundamentação ética legitimadora do investimento público na proteção das pessoas mais fracas e vulneráveis, o que consubstancia o núcleo essencial do Estado Democrático de Direito. Portanto, incumbe aos Poderes Públicos adotar medidas concretas para estimular a iniciativa privada, mediante substanciais investimentos em infraestrutura, além da concessão de incentivos fiscais, tudo de forma a gerar o aumento de produtividade e, por decorrência, novos empregos. Estratégias da política econômica do Estado, como essas, suscitam condições plausíveis para agregar parceiros da área econômica e universitária, no intuito de destravar a economia em prol do bem de todos.

Da viabilização dessas parcerias pode resultar a proposição de novas diretrizes para o afrontamento das presentes e futuras exigências de mudanças sistêmicas e tecnológicas derivadas da quarta revolução. Assim, urge centralizar interesses na primazia do acesso ao trabalho decente como expressão da pessoa humana, jungidos ao fortalecimento da concepção institucional e comunitária de empresa no pleno exercício de sua função social, nos termos do

13 DOWBOR, Ladislau. Democracia Econômica: alternativas de gestão social. Petrópolis, RJ: Editora Vozes, 2008, p.p. 166,168 e 169. 
citado art. 170 da Constituição Federal, inclusive para o alcance de uma economia mais solidária, humana e justa.

Impõe-se, portanto, no âmbito de um Estado Democrático de Direito, manter as conquistas dos trabalhadores compatíveis com a sua dignidade humana, mesmo diante dos efeitos nefastos do neoliberalismo instalado, de modo a assegurar o devido acesso ao trabalho decente, como vem proclamando a Organização Internacional do Trabalho - OIT. Sua trajetória evolutiva direciona-se à realização de valores em prol da proteção do trabalho digno, aliada ao ambiente saudável e seguro, para impedir que o ser humano seja tratado como mera mercadoria. Por isso, para justificar a razão de sua existência, a OIT vem ressaltando e difundindo, em nível internacional, que todo trabalhador, independentemente da raça e nacionalidade, deve ter sua dignidade respeitada e tutelada, em qualquer lugar do planeta, de modo a concretizar efetivamente as condições relativas ao trabalho decente. Desse modo, preocupada com o futuro do trabalho, em janeiro de 2019, a OIT publicou o "Relatório Trabalhar para um Futuro mais Promissor", onde coloca "homens, mulheres e o trabalho que eles fazem no centro das políticas econômicas e sociais e da prática empresarial, diante do conflitante cenário de expansão da tecnologia e informação:

Esse programa baseia-se em três linhas de ação que, combinadas, gerariam crescimento, igualdade e sustentabilidade para as gerações atuais e futuras. Suas finalidades são voltadas a aumentar o investimento nas capacidades das pessoas; aumentar o investimento em instituições trabalhistas e aumentar o investimento em trabalho decente e sustentável, de modo a obter mais segurança econômica, igualdade de oportunidades e justiça social. ${ }^{14}$

Portanto, cumpre ao Estado brasileiro - membro da OIT - adotar políticas públicas eficazes, de forma coordenada e contínua, para colocar à disposição de todos os trabalhadores, principalmente dos desempregados, a imprescindível formação educacional, técnica e profissional adequadas às permanentes transformações econômicas e sociais, a exemplo do que vem sustentando a UNESCO - Organização das Nações Unidas para a Educação, Ciência e Cultura:

Existe a necessidade de promoção da educação e formação técnica e profissional - EFTP - no Brasil para preparar a juventude para o mercado de trabalho, aumentar o crescimento econômico e reduzir a pobreza.

14 OIT - COMISSÃO MUNDIAL SOBRE O FUTURO DO TRABALHO. Disponível em: <https://www.ilo.org/infostories/es-ES/Campaigns/future-work/global-commission\#intro>.Acesso em: 16jun. 2021. 
A EFTP pode ligar a educação e o mercado de trabalho, pois ela visa a tratar de demandas econômicas, sociais e ambientais ao ajudar os jovens e os adultos a desenvolver as habilidades que precisam para adquirirem emprego, trabalho decente e desenvolverem o empreendedorismo. Assim, a EFTP promove o crescimento econômico igualitário, inclusivo e sustentável, além de dar assistência a transições [...].

A UNESCO apoia ações relativas ao desenvolvimento de competências de gestores e de equipes técnicas, no que se refere ao planejamento e à execução de ações que incrementem o acesso à educação, a permanência de estudantes nas escolas, a eficiência e a eficácia da educação profissional oferecida à população brasileira. ${ }^{15}$

Nesse contexto, se ao Estado-administração, sob o comando do Poder Executivo, compete propiciar meios efetivos, para se alcançar uma economia verdadeiramente mais humana e com fins sociais, ao Judiciário Trabalhista incumbe fazer uso do processo como poderoso instrumento ético para dar plena efetividade ao Direito do Trabalho. Por meio de uma interpretação evolutiva, suas normas tendem a ser adequadas às diversas realidades contemporâneas. Por decorrência, concretiza efetivamente o princípio constitucional da dignidade da pessoa humana, aliado ao princípio da valorização do trabalho. E, assim, diante de cada caso concreto, ao reavaliar os critérios de configuração da subordinação jurídica diante dos avanços tecnológicos, tem como reconhecer e assegurar o exercício dos direitos fundamentais desses trabalhadores lançados ao desenvolvimento de novas atividades, em condições que se distanciam dos contornos rígidos do contrato individual de trabalho clássico. De qualquer forma, a obrigação assumida de prestar diversos serviços, no âmbito de uma sociedade em rede, digitalizada, por si só, não induz o trabalhador a renunciar seus direitos, mesmo porque são irrenunciáveis.

Assim, mostra-se necessário buscar o meio termo aristotélico, para que as transformações apontadas não desconsiderem o primado da dignidade da pessoa humana e do valor social do trabalho, em conjunto e de forma não excludente com o vetor da livre iniciativa, pois todos são fundamentos da República Federativa do Brasil (art. $1^{\circ}$, incisos III e IV, da Carta Magna).

As empresas em rede ofertam trabalho. O problema é saber que modalidade de labor, por qual salário e em quais condições. O capital incentiva a cooperação e o empreendedorismo e enaltece a autonomia, o que fragmenta os trabalhadores. $\mathrm{O}$ capitalismo informacional impõe colaboradores descartáveis, genéricos ou flexíveis $[\ldots]$.

Essas tecnologias comunicacionais propiciam uma mutação na relação capital e o trabalho, para maximizar a acumulação flexibilizada. O capitalismo se reinventa para permanecer no controle do poder. ${ }^{16}$

15 REPRESENTAÇÃO DA UNESCO NO BRASIL. Educação e formação técnica e profissional no Brasil. Disponível em: <http://www.unesco.org/new/pt/brasilia/education/educational-quality/technical-andvocational-education/>. Acesso em 16 jun.2021.

16 MELO, Geraldo Magela. A Reconfiguração do Direito do Trabalho a partir das Redes Sociais Digitais. São Paulo: LTr, 2018, p. 78. 
A feição virtual adquirida pelo empregador, com a implantação progressiva desse sistema de dominação tecnológica, fortalece seu poder de fiscalização dos empregados durante a prestação de serviços e, também, fora do ambiente de trabalho, com possibilidades de invasão da vida pessoal e íntima dos obreiros, inclusive de forma a configurar o cyberbulling. Essa forte ingerência deve ser combatida por todos os meios legais. Por tudo isso, ao contrário dessas negativas implicações, no âmbito das plataformas de relacionamento, "deve-se entender que as redes sociais online podem viabilizar laços positivos de convivência no ambiente de trabalho e fora dele, inclusive com possibilidade de colaboração mútua entre os membros das comunidades virtuais". ${ }^{17}$

Nessa senda, impõe-se fortalecer e readequar o Direito do Trabalho à realidade da flexibilização da produção, eis que o avanço da tecnologia, por si só, conduz à precarização das relações de trabalho, afrontando valores, princípios e regras constitucionais, além de normas internacionais de proteção dos direitos humanos. Desse modo, rebaixa o conquistado padrão civilizatório dos trabalhadores, o que é inadmissível sob a égide do Estado Democrático de Direito. É preciso ressaltar que "o desenvolvimento tecnológico não pode representar uma impossibilidade de proteção ao trabalhador, mas, ao contrário, deve agir de forma a proporcionar mais proteção", como sustenta Domingos Monteiro, aduzindo ainda que

A era digital não pode e não deve ser o sepultamento do Direito do Trabalho, reduzindo esse à proteção dos trabalhadores de raros contratos formais, se a sociedade muda, se os conceitos de trabalho mudam, se a forma de produção muda, o Direito do Trabalho não deve ser estático, e o seu dinamismo poderá iniciar pelos operadores do direito na interpretação diária das normas de proteção. ${ }^{18}$

Diante de todas essas inovadoras circunstâncias, resta à Judiciário Trabalhista atuar com rigor, racionalidade e sensibilidade, de modo condizente com a realização da justiça. Isso significa que os desafios impostos pela evolução do sistema de plataformas digitais - ao introduzir novos tipos e formatos de relações de trabalho - consolidam a urgência de se elevar o grau de aplicação e de eficácia dos princípios da proteção e da primazia da realidade que informam o Direito do Trabalho. Nesse passo, as alegações referentes ao denominado trabalho sob demanda exigem a produção de prova capaz de apurar a existência, ou não, dos elementos fático-jurídicos contidos nos art. $2^{\circ}, 3^{\circ}$ e $6^{\circ}$, parágrafo único, da CLT, no sentido de se afastar a

17 Idem, p. 83.

18 Monteiro, Daniele Domingos. O Trabalho sob demanda - Uberização das relações de trabalho e os desafios do Direito do Trabalho. In: Guilherme Guimarães Feliciano, Ana Paula Silva Campos Miskulin (Coords). Infoproletários e a Uberização do Trabalho: direito e justiça em um novo horizonte de possibilidades. São Paulo: LTr, 2019, p. 73. 
tentativa de burla da legislação trabalhista e, ipso facto, reconhecer a existência de relação de emprego.

Bem oportunas são as reflexões de Guilherme Guimarães Feliciano e Olívia de Quintana Figueiredo Pasqualeto:

\begin{abstract}
É preciso que as linhas mestras do Direito do Trabalho, outrora compatíveis com as necessidades da sociedade pré-industrial- mas agora erodidas para fins de subsunção e tratamento das relações de trabalho uberizadas - adequem-se às novas formas de contratação, como o crowdwork e o work on-demand via app, e, identificando, na matriz constitucional, quais direitos do rol do art. $7^{\circ}$, da $\mathrm{CF}$, tutelam diretamente esses trabalhadores, e de que modo o fazem [...]
\end{abstract}

O Poder Judiciário passa a ter papel fundamental a desempenhar nesse particular. Sua legitimidade para esse mister não é estritamente política; antes, é sobretudo técnica, revelando a modulação do Estado Democrático, segundo o Direito (e não apenas segundo a vontade da maioria). E, no exercício dessa legitimidade, pode também reconhecer e aplicar limitações à autonomia privada (individual ou coletiva), com o amparo no sistema de princípios ínsito à Constituição e às leis [...].

A ideia de contrato pressupõe o livre consentimento e a manifestação de vontade declarada de forma inteligível. Muitas vezes, porém, essa declaração não é clara, a ponto de não se poder afirmar, sequer com base no princípio da boa fé objetiva (art. 422, do Código Civil), que o pacto tenha engendrado vinculação contratual quanto a determinado(s) aspecto(s) (=quadros de indefinição do conteúdo volitivo). Pois bem: a ausência de clareza ou até mesmo de declaração expressa é pouco relevante no Direito do Trabalho, já que o contrato de trabalho revela-se como um contrato realidade a dispensar, inclusive, qualquer elemento volitivo ou cognitivo. Tal constatação resgata a institucionalidade da relação de emprego e provoca um retorno sutil e paulatino às teorias anticontratualistas. E é sob nova clivagem hermenêuticoaplicativa que poderemos inclusive ressignificar os elementos da relação de emprego, repensando os pressupostos da subordinação (de base estrutural?), da pessoalidade (de tipo virtual ?), da onerosidade (com viés espectal?) e não eventualidade (meramente tendencial?

Com base nessas assertivas e questionamentos, pode - e deve - resultar, mesmo que gradualmente, a transformação dessa dura e injusta realidade de exclusão de muitos trabalhadores da garantia dos direitos fundamentais sociais do trabalho. Através da melhor adequação do Direito do Trabalho à realidade da flexibilização do mercado de trabalho, regido pela tecnologia de plataformas, os efeitos da prestação jurisdicional restabelecem a justiça e a paz social entre as partes, no processo trabalhista. Assim, além de assegurar a plena efetividade aos direitos fundamentais dos trabalhadores, à luz da Constituição da República Federativa do Brasil, as decisões judiciais impõem limites aos propósitos de natureza econômica que buscam afastar o equilíbrio dessa relação cada vez mais assimétrica entre empregado e empregador. 


\section{CONSIDERAÇÕES FINAIS}

Não há como se alcançar o desenvolvimento sustentável do País sem o acesso à educação de qualidade e ao trabalho decente, principalmente diante de milhões de pessoas analfabetas e desempregadas, que compõem os maiores índices de exclusão social, inclusive em decorrência da pandemia do Covid-19.

Convém lembrar que a própria Lei Maior faz a conexão direta entre educação e trabalho, nos termos do art. 205, ao exigir a realização desses direitos, também pelo Estado, a exemplo dos demais direitos sociais elencados no art. $6^{\circ}$, cuja efetivação não se sujeita à vontade política. Portanto, não se pode mais tolerar a notória acomodação dos orgãos públicos competentes, quase sempre justificada - de forma até mesmo evasiva - pela escassez de recursos financeiros.

Nesse sentido, a realidade atual atesta que os direitos humanos e fundamentais sociais dos trabalhadores, não raro, deixam de ser assegurados mesmo no seio de uma sociedade democrática regida pela Constituição Federal e pela força vinculante dos Tratados Internacionais dos Direitos Humanos. São muitos trabalhadores lançados no mercado informal e submetidos a diversas modalidades de prestação de serviços guiadas por plataformas que dependem totalmente da força humana de trabalho, mas as empresas contratantes, com relação a eles, se apresentam despidas de qualquer responsabilidade social, fiscal e trabalhista. Ora, o Estado Democrático de Direito destina-se a assegurar o exercício dos direitos sociais como valores supremos, isto é, que merecem tratamento prioritário. São dotados de exigência ética, juridicamente garantidos, de modo a concretizar a realização dos objetivos fundamentais da República Federativa do Brasil, direcionados à promoção do bem de todos. Portanto, urge assegurar a satisfação de direitos que não podem ser negligenciados, o que exige da administração pública eficientes estratégias de estímulo à economia mais humana e à criação de empregos.

Para tanto, o Estado, mediante a realização transparente da justiça redistributiva, tem como direcionar a formação de parcerias público-privadas, tendentes ao alcance de etapas mais progressistas e inovadoras de produção. Além disso, a geração de novos negócios e postos de trabalho, como se sabe, depende de segurança jurídica e estabilidade das relações sociais, por parte dos Poderes Públicos, principalmente diante da dinâmica gig economy. Por outro lado e nessas circunstâncias, também devem as empresas bem exercer sua função social, dando prevalência à dimensão humana em prol da satisfação dos direitos fundamentais, de modo a garantir a todos existência digna (CRFB, art. 170). 
Enfim, constitui relevante tarefa da Justiça do Trabalho enfrentar o grande desafio de retirar aquele rótulo que, de certa forma, vem servindo para generalizar como independentes todos os trabalhadores que atuam sob demanda via aplicativos, para o devido enquadramento na condição de empregados, nos termos dos artigos $2^{\circ}$ e $3^{\circ}$, da Consolidação das Leis do Trabalho, diante de cada caso concreto. Assim, ao aplicar os princípios e regras constitucionais, assegura o pleno exercício dos devidos direitos trabalhistas. Nesse cenário e com equilíbrio, as decisões judiciais proferidas resguardam, igualmente, o princípio da conservação da empresa, pois esta, no pleno exercício de sua função social, propicia o espaço destinado ao exercício da cidadania com responsabilidade por parte de todos aqueles que dela fazem parte, com mais destaque os empregados, além de outros trabalhadores e colaboradores. Urge restabelecer o equilíbrio dessa relação jurídica de trabalho cada vez mais assimétrica entre empregado e empregador, assegurando a centralização do valor da pessoa humana no mundo do trabalho, sob a égide do Estado Democrático de Direito.

\section{REFERÊNCIAS BIBLIOGRÁFICAS}

ALQUÉRES, Hubert. O Novo Conhecimento. O desafio da educação é formar jovens para empregos que ainda não foram criados. In: Revista Cult, $n^{\circ} 246$. São Paulo: Editora Bregantini, junho de 2019.

BRASIL. IBGE/2019.

Disponível:<https://agenciadenoticias.ibge.gov.br/media/com_mediaibge/arquivos/00e02a8bb 67cedc4fb22601ed264c00.pdf>acesso em: 27abril 2021.

BRASIL, Lei 12.965, de 24 de abril de 2014. Disponível em: <http://www.planalto.gov.br/ccivil_03/_ato2011-2014/2014/lei/112965.htm>. Acesso em: 27fev. 2021.

COLLIER, PAUL. O Futuro do Capitalismo: enfrentando as novas inquietações. Trad. Denise Bottmann. Porto Alegre: L\&PM, 2019.

DOWBOR, Ladislau. Democracia Econômica: alternativas de gestão social. Petrópolis, RJ: Editora Vozes, 2008.

FELICIANO, Guilherme Guimarães; PASQUALETO, Olívia de Quintana Figueiredo. (Re)descobrindo o Direito do Trabalho: Gig Economy, Uberização do trabalho e outras reflexões. In: Guilherme Guimarães Feliciano, Ana Paula Silva Campos Miskulin (Coords.). Infoproletários e a Uberização do Trabalho: direito e justiça em um novo horizonte de possibilidades. São Paulo: LTr, 2019.

KIM, Richard Pae. O Conteúdo Jurídico da Cidadania na Constituição Federal do Brasil. In: MORAES, Alexandre; KIM, Richard Pae (Coords.). Cidadania. O novo conceito jurídico e 
a sua relação com os direitos fundamentais individuais e coletivos. São Paulo: Editora Atlas S/A. 2013.

LEE-KAI FU. Inteligência Artificial: como os robôs estão mudando o mundo, a forma como amamos, nos comunicamos e vivemos. Trad. Marcelo Barbão. Rio de Janeiro: Globo Livros, 2019

LIMA, Carolina Alves de Souza. Cidadania, Direitos Humanos e Educação: avanços, retrocessos e perspectivas para o século 21. São Paulo: Almedina, 2019.

MELO, Geraldo Magela. A Reconfiguração do Direito do Trabalho a partir das Redes Sociais Digitais. São Paulo: LTr, 2018.

MONTEIRO, Daniele Domingos. O Trabalho sob demanda - Uberização das relações de trabalho e os desafios do Direito do Trabalho. In: Guilherme Guimarães Feliciano, Ana Paula Silva Campos Miskulin (Coords.). Infoproletários e a Uberização do Trabalho: direito e justiça em um novo horizonte de possibilidades. São Paulo: LTr, 2019.

OIT - COMISSÃO MUNDIAL SOBRE O FUTURO DO TRABALHO. Disponível em: <https://www.ilo.org/infostories/es-ES/Campaigns/future-work/global-commission\#intro>. Acesso em: 16 jun. 2021.

PIOVESAN, Flávia. Direitos Humanos e o Direito Constitucional Internacional. $18^{\text {a }}$ Ed., Saraiva: São Paulo, 2018.

REPRESENTAÇÃO DA UNESCO NO BRASIL. Educação e formação técnica e profissional no Brasil. Disponível em:

<http://www.unesco.org/new/pt/brasilia/education/educational-quality/technical-andvocational-education/>. Acesso em 16 jun.2021.

SCHWAB, Klaus. A Quarta Revolução Industrial. Trad. Daniel Moreira Miranda. São Paulo: Edipro, 2016.

SINGER, Paul. A cidadania para todos. In: PINSKY, Jaime; PINSKY, Carla Bassanesi. História da Cidadania. $3^{\text {a }}$ ed., São Paulo: Contexto, 2005.

TIROLE, Jean. Economia do Bem Comum. Rio de Janeiro: Jorge ZAAR Editor, 2020.

Data de aprovação: 01/07/2021

Data de publicação: 27/07/2021

Este trabalho é publicado sob uma licença Creative Commons Attribution 4.0 International License. 